\title{
Ponovljivost odabranih metoda za određivanje fenola u urinu tekućinskom kromatografijom visoke djelotvornosti
}

\author{
E. Horozić, ${ }^{a^{*}}$ A. Begić, ${ }^{b}$ Z. Ademovića i S. Brekalo Lazarevićc \\ a Tehnološki fakultet, Univerzitet u Tuzli, Univerzitetska 8, 75000 Tuzla, BiH \\ ' Farmaceutski fakultet, Univerzitet u Tuzli, Univerzitetska 8, 75000 Tuzla, BiH \\ cMedicinski fakultet, Univerzitet u Tuzli, Univerzitetska 1, 75000 Tuzla, BiH
}

DOI: $10.15255 / K U I .2018 .016$

KUI-51/2018

Prispjelo 17. travnja 2018.

Prihvaćeno 7. lipnja 2018.

\section{Sažetak \\ Određivanje fenola u urinu smatra se prikladnim biomarkerom izloženosti benzenu, koji je klasificiran u grupu A kancerogena od strane Međunarodne agencije za istraživanje raka (IARC) i Agencije za zaštitu okoliša (EPA). \\ U ovom radu testirana je ponovljivost nekoliko metoda za analizu fenola u urinu primjenom tekućinske kromatografije visoke djelotvornosti. Publicirane metode uglavnom uključuju dodatnu opremu koja nije standardna (npr. fluorescentni detektor) ili dodatne postupke u pripremi uzoraka kao što su parna destilacija ili derivatizacija, što produljuje vrijeme potrebno za pripremu uzoraka ili se povećava mogućnost gubitka dijela sadržaja analita. Odabrana je metoda koja se pokazala reproducibilnom uz određene modifikacije. Izmjena metode uključivala je promjenu valne duljine, sastava i protoka mobilne faze, te je isključilo primjenu internog standarda u proceduri pripreme uzoraka urina za analizu. Kao mobilna faza upotrijebljena je smjesa destilirane vode/metanola/acetatne kiselina (65:34:1 v/v\%), a upotrijebljena je kolona Selectra C18 $(4.6 \times 250 \mathrm{~mm}, 5 \mu \mathrm{m})$. Uvjeti kromatografiranja bili su protok $1 \mathrm{ml} \mathrm{min}^{-1}$, temperatura kolone $25{ }^{\circ} \mathrm{C}$, valna duljina 218 i 270 nm i volumen injektiranja $20 \mu \mathrm{l}$. Pri valnoj duljini $270 \mathrm{~nm}$ metoda je pokazala linearnost u koncentracijskom opsegu $1-30 \mathrm{mg} \mathrm{I}^{-1}(\mathrm{y}=10290 \mathrm{x}+15138$; $\left.R^{2}=0,9932\right)$, a iskorištenost metode kreće se u rasponu od 73,8 do $111,2 \%$.}

\section{Ključne riječi}

Fenol, ekstrakcija, urin, HPLC

\section{Uvod}

Fenol (hidroksibenzen) jedan je od metabolita benzena i može poslužiti kao biomarker za mjerenje razine izloženosti benzenu. Benzen je poznati zagađivač okoliša prisutan u zraku pri koncentracijama u rasponu od ppb u ruralnim i urbanim okruženjima do ppm na nekim radnim mjestima. Odnos između razina izloženosti benzenu i metabolitima benzena važan je za razumijevanje potencijalnih rizika za zdravlje ljudi. ${ }^{1}$ Metabolizam benzena prikazan je na slici 1.

Fenol, hidrokinon i katehol glavni su metaboliti benzena, a njihova zastupljenost u organizmu dovodi do hematotoksičnosti. ${ }^{2}$ Zbog široke upotrebe benzena nužno je obratiti pozornost na njegovu toksičnost u okolišu. ${ }^{3}$ Spojevi benzena mogu se oslobađati u okoliš putem industrijskih otpadnih voda, uključujući industriju ugljena, industrije smole, industrije boje, pesticide, lijekove, kozmetičke proizvode i dr. ${ }^{4}$ Ispitivanjem je utvrđeno da kada su količine fenola u 24-satnom urinu manje od $40 \mathrm{mg}$, to odgovara koncentracijama benzena u zraku manjim od $100 \mathrm{mg} \mathrm{m}^{-3}$. S druge strane, količine fenola u 24-satnom urinu od otprilike $100 \mathrm{mg}$ odgovaraju vrijednostima benzena u zraku od $100 \mathrm{mg} \mathrm{m}^{-3} .{ }^{5}$ Mnogi znanstvenici ispitivali su različite metode određivanja fenola u urinu, poput spektrometrije, tekućinske kromatografije visoke djelotvornosti, plinovite kromatografije i dr. ${ }^{6,7,8}$ Objavljene metode uglavnom uključuju dodatnu opremu koja nije standardna (npr. fluorescentni detektor ${ }^{9}$ ) ili dodatne postupke u pripremi uzoraka kao što su parna destilacija ${ }^{10}$ ili derivatizacija, ${ }^{9}$ što produljuje vrijeme potrebno za pripremu uzoraka ili se povećava mogućnost gubitka dijela sadržaja analita.

Metoda koju je predložio Alawi 2008. godine ${ }^{10}$ uključuje izokratsku separaciju, kolonu C18, mobilnu fazu sastava metanol, voda i glacijalna acetatna kiselina, protok

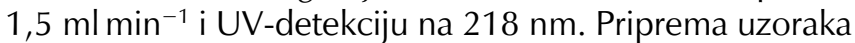
urina za određivanje sadržaja fenola tom metodom uključuje parnu destilaciju. Destilat se zatim alkalizira, a potom se doda $\mathrm{NaCl}$ i protrese nekoliko minuta. Nakon dodatka etilacetata u smjesu nastavi se tresti 5 min i na kraju se organski sloj odbacuje. Vodeni sloj se zatim 
zakiseli s nekoliko kapi $\mathrm{HCl}$, doda se $2 \mathrm{ml}$ etilacetata $\mathrm{u}$ kojem je sadržano 5 ppm p-krezola i trese 5 min. Vodeni sloj se odbacuje a organski sloj analizira. Uz navedene uvjete autori su objavili granicu detekcije $0,05 \mu \mathrm{g} \mathrm{ml}^{-1}$ fenola i postotak efikasnosti ekstrakcije fenola $83-107 \%$ u koncentracijskom opsegu $1-10 \mu \mathrm{g} \mathrm{ml}^{-1}$.

Metoda koju su 1995. objavili Birkett $i$ sur. ${ }^{11}$ uključuje izokratsku separaciju, kolonu C18, mobilnu fazu sastava metanol s $0,02 \mathrm{moll}^{-1}$ fosfatnim puferom $\mathrm{pH}$ 4.0, protok $0,7 \mathrm{ml} \mathrm{min}^{-1}$ i UV-detekciju na $270 \mathrm{~nm}$. Priprema uzoraka urina za određivanje sadržaja fenola obuhvaća izravno dodavanje koncentrirane $\mathrm{HCl}$ i otopine internog standarda $p$-krezola u urin i otopina se ostavi vrijeti. Nakon hlađenja fenoli se ekstrahiraju dietileterom, nakon čega se mješavina centrifugira. Organski sloj se aspirira s $\mathrm{NaOH} u$ metanolu. Rezultirajuća otopina ostavi se ispariti do suhog ostatka u struji nitrogena i ostatak se rekonstituira s destiliranom vodom. Primjenom navedene metode autori su objavili granicu detekcije $0,2 \mu \mathrm{g}$ fenola i postotak efikasnosti ekstrakcije fenola od $98 \%$ za $40 \mu \mathrm{g}$ fenola.

Cilj ovoga rada bio je testirati ponovljivost (reproducibilnost) tih ranije objavljenih metoda za određivanje fenola u urinu primjenom tehnike tekućinske kromatografije visoke djelotvornosti (HPLC) te pojednostaviti protokol pripreme uzoraka urina za analizu.

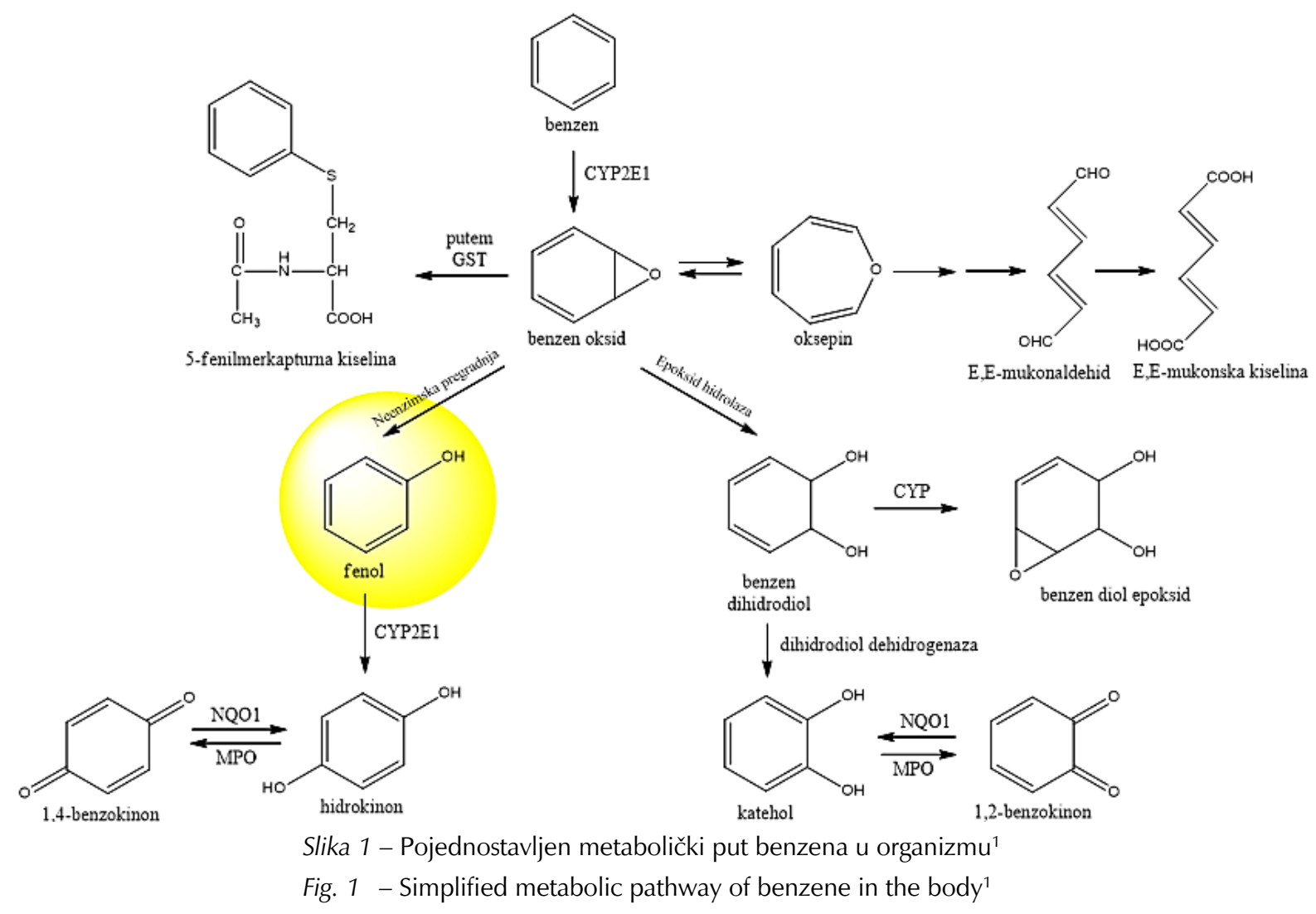

\section{Eksperimentalni dio}

\subsection{Kemikalije}

Referentni standard fenola, dietileter i acetatna kiselina nabavljeni su od tvrtke Sigma-Aldrich, Njemačka, dok je metanol čistoće HPLC nabavljen od tvrtke Bisolve Chimie, Francuska. Klorovodična kiselina i natrijev hidroksid nabavljeni su od tvrtke Roth, Njemačka.

\subsection{Aparatura}

Za kvantitativnu analizu fenola u urinu primijenjen je sustav HPLC (Shimadzu, Japan) koji se sastoji od rezervoara mobilne faze, pumpe, autosemplera, pećnice i detektora UV/VIS. Za razdvajanje komponenti odabrana je kolona Selectra C18 $(4.6 \times 250 \mathrm{~mm}, 5 \mu \mathrm{m})$, podešen protok $1 \mathrm{ml} \mathrm{min}{ }^{-1}$, valne duljine na $218 \mathrm{~nm}$ i $270 \mathrm{~nm}$ i volumen iniciranja $20 \mu \mathrm{l}$. Izokratsko eluiranje je izvedeno uz sustav mobilne faze destilirana voda : metanol : acetatna kiselina (65: $34: 1 \mathrm{v} / \mathrm{v} \%)$. Za kontrolu instrumenta, prikupljanje i analizu podataka primijenjen je softver LabSolutions Mainsystem i Nexera (Shimadzu 2008-2010). 


\subsection{Priprema standardnih otopina}

Za snimanje kromatograma pripremljene su otopine referentnog standarda fenola $\mathrm{u}$ destiliranoj vodi $\mathrm{u}$ koncentracijskom opsegu od 1 do $30 \mathrm{mgl}^{-1}$. Pripremljena je osnovna otopina fenola koncentracije $50 \mathrm{mgl}^{-1}$ iz kojeg su dalje spravljana odgovarajuća razblaženja. Odabir koncentracijskog područja ponajprije je prilagođen koncentracijama fenola koje su utvrđene kod radnika u kemijskoj industriji s područja Tuzlanskog kantona.

\subsection{Priprema uzorka urina}

Postupak pripreme uzoraka ranije su objavili Birket $i$ sur., ${ }^{11}$ s time što je izuzeto dodavanje internog standarda. Prikupljeni uzorak urina za analizu centrifugiran je 15 min na $4000 \mathrm{rpm}$. Nakon toga je dodano $2 \mathrm{ml}$ koncentrirane $\mathrm{HCl}$ i u nastavku je provedeno inkubiranje u vodenoj kupelji pri temperaturi $90^{\circ} \mathrm{C}$. Nakon sat vremena uzorci su izvađeni iz vodene kupelji i ohlađeni na sobnu temperaturu. $U$ ohlađene uzorke dodano je $4 \mathrm{ml}$ dietiletera, koji se zatim protresu $1 \mathrm{~min}$ i nakon toga centrifugiraju $10 \mathrm{~min}$ na $1800 \mathrm{rpm}$. Eterski sloj nakon centrifugiranja kvantitativno se prenese u epruvete u koje je prethodno dodano $3 \mathrm{ml} \mathrm{NaOH}$ otopljenog u metanolu $\left(c=0,05 \mathrm{moll}^{-1}\right)$. Sadržaj epruvete se protrese, eter se otpari i uzorci se rekonstituiraju s $0,5 \mathrm{ml}$ destilirane vode. Prije prenošenja u vijale uzorci se filtriraju.

\section{Rezultati i rasprava}

Primjena metode za pripremu uzorka urina koju je 2008. godine predložio Alawi ${ }^{10}$ i koja uključuje parnu destilaciju i ekstrakciju s etilacetatom nije pokazala dobru ponovljivost. Ne samo da parna destilacija predstavlja dodatni korak u pripremi uzoraka i dodatnu opremu, već ljepljivost mješavine nakon dodatka etilacetata i $\mathrm{NaCl}$ otežava ekstrakciju. Metoda koju su 1995. godine predložili Birkett $i$ sur. ${ }^{11}$ pokazala se ponovljivom uz uspješnu ekstrakciju fenola iz urina prema propisanom protokolu pripreme uzoraka. Budući da priprema uzoraka podrazumijeva vrenje $\mathrm{u}$ trajanju od $1 \mathrm{~h}$, s ciljem skraćivanja i pojednostavljivanja procedure pripreme uzoraka urina za analizu, testirani su i drugi postupci pripreme. Urin je tretiran perklornom kiselinom i zagrijavan 10 min u vodenoj kupelji pri temperaturi vrenja, nakon čega je fenol ekstrahiran dietileterom koji je potom otparen, a ostatak rekonstituiran u destiliranoj vodi.

To skraćivanje tretmana uzorka urina na povišenoj temperaturi rezultiralo je nedovoljnom efikasnosti ekstrakcije fenola (50\%). Uzimajući u obzir prisutnost fenola $u$ urinu $u$ formi konjugata sa sulfatnom ili glukurunskom kiselinom, u svrhu postizanja efikasnije hidrolize konjugata testirano je više kiselina. Pokazano je da se ipak primjenom $\mathrm{HCl}$ postiže najefikasnija hidroliza i ekstrakcija fenola. Dakle, zadržan je postupak pripreme uzoraka koji su predložili Birkett $i$ sur., s time što je izuzeto dodavanje internog standarda, budući da ekstrakcija $p$ krezola iz urina nije bila efikasna. Odlučeno je da se sastav mobilne faze koji je predložio Alawi zadrži, kako bi se izbjegla primjena pufera, a protok je podešen na $1 \mathrm{ml} \mathrm{min}{ }^{-1}$. Budući da dvije metode podrazumijevaju detekciju na različitim valnim duljinama, odlučeno je da se testiraju uzorci na obje predložene valne duljine $(218 \mathrm{~nm}$ i $270 \mathrm{~nm})$.

Selektivnost je demonstrirana usporedbom vremena zadržavanja fenola u uzorcima $(n=10)$ i standardnim otopinama. Na $270 \mathrm{~nm}$ nisu zabilježeni interferirajući pikovi (slika 5).

Linearnost metode postignuta je $\mathrm{u}$ opsegu koncentracija $1-30 \mathrm{mgl}^{-1}$ na obje valne duljine. Međutim preciznost nije postignuta na $218 \mathrm{~nm}$ (visoke vrijednosti koeficijenata varijacije), vjerojatno zbog interferencije $s$ nekom komponentom iz matriksa. Linearnost fenola $u$ standardnim otopinama, odnosno špikanim uzorcima urina na $270 \mathrm{~nm}$ prikazana je na slikama 2 i 3.

Standardna otopina fenola pokazala je dobru ponovljivost vremena zadržavanja i površina ispod kromatografske krivulje za fenol na više koncentracijskih razina (vrijednosti RSD-a za površine: $1 \mathrm{mgl}^{-1}, 87 \%$ i $30 \mathrm{mgl}^{-1} 0,31 \%$ ).

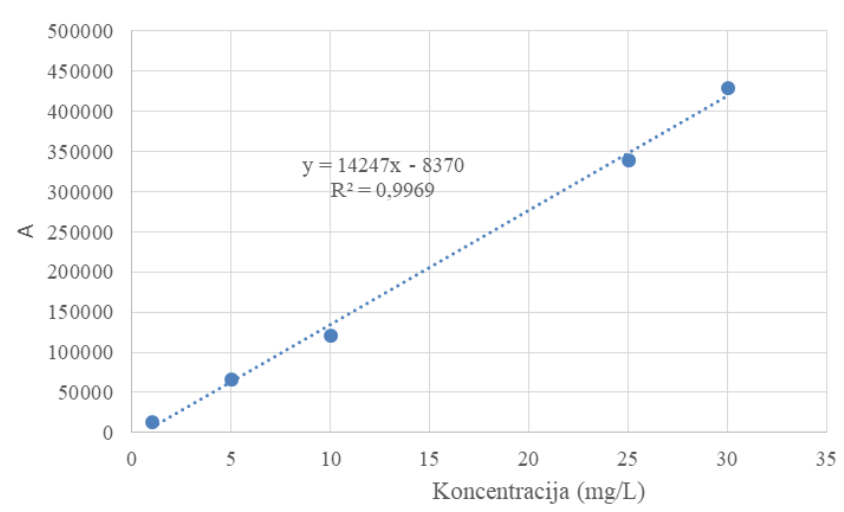

Slika 2 - Linearnost fenola u standardnim otopinama pri valnoj duljini $270 \mathrm{~nm}$

Fig. 2 - Linearity of phenol in standard solutions at wavelength $270 \mathrm{~nm}$ 


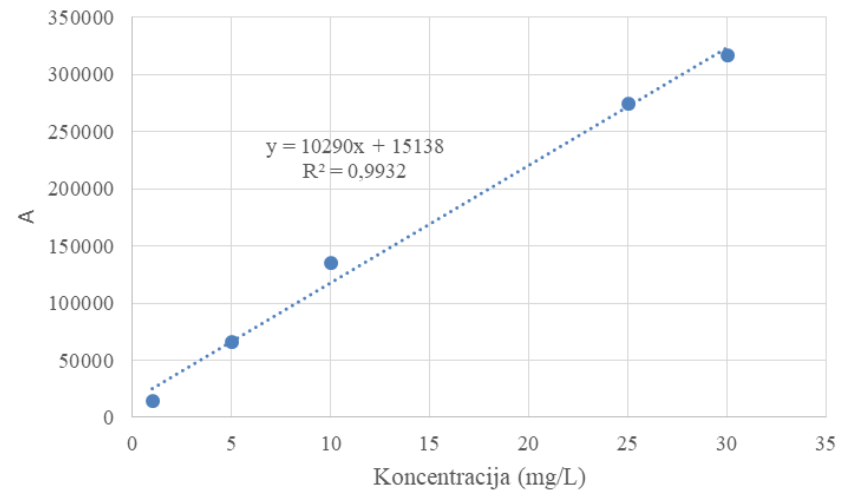

Slika 3 - Linearnost fenola u špikanim uzorcima urina pri valnoj duljini $270 \mathrm{~nm}$

Fig. 3 - Linearity of phenol in spiked urine samples at wavelength $270 \mathrm{~nm}$

Preciznost je utvrđena na osnovi koeficijenata varijacije za površine ispod kromatografske krivulje fenola u zasićenim uzorcima urina (RSD za pet uzastopnih analiza na tri koncentracijske razine) i zabilježene su vrijednosti: 1,65\% $\left(5 \mathrm{mg} \mathrm{l}^{-1}\right)$, 4,39 \% (10 $\left.\mathrm{mgl}^{-1}\right)$ i 2,60 \% (30 $\left.\mathrm{mgl}^{-1}\right)$. Najniža granica detekcije dobivena je statistički, na osnovi standardne pogreške predviđenih vrijednosti y za svaki x u regresiji (STEYX). Izračunat je na osnovi standardne devijacije odgovora i nagiba definirane kalibracijske krivulje:

$$
\mathrm{LLOD}=\frac{3 \cdot \mathrm{STDEV}}{b}
$$

pri čemu je $b$ nagib kalibracijskog pravca.

Najniža granica detekcije iznosi 1,47 $\mathrm{mgl}^{-1}$.

Točnost je utvrđena na osnovi razlike (\% bias) između očekivane i izmjerene koncentracije. $U$ tu je svrhu testirana na tri koncentracijske razine i dobiveni su sljedeći rezultati: $5 \mathrm{mgl}^{-1}$ (-2\%), $10 \mathrm{mgl}^{-1}(5,7 \%)$ i $30 \mathrm{mgl}^{-1}(-4,26 \%)$.
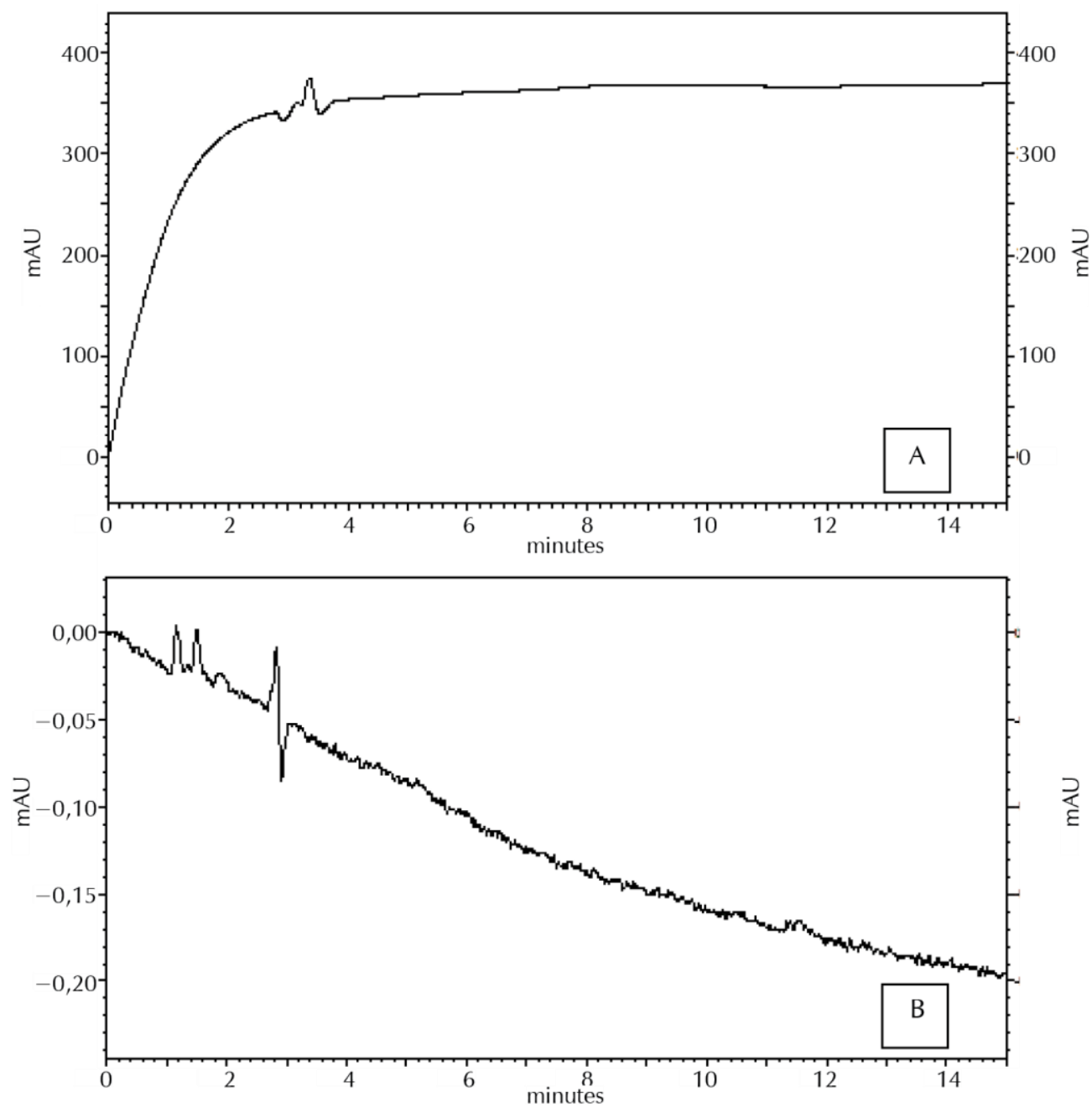

Slika 4 - Kromatogrami mobilne faze: (A) na $218 \mathrm{~nm}$; (B) na $270 \mathrm{~nm}$

Fig. 4 - Chromatograms of mobile phase: (A) at $218 \mathrm{~nm}$; (B) at $270 \mathrm{~nm}$ 
Testirana je i kratkoročna stabilnost uzoraka na sobnoj temperaturi $(24$ h), pri čemu je zabilježen gubitak od $31 \%$ već na najvišoj testiranoj koncentracijskoj razini od $30 \mathrm{mgl}^{-1}$ i $78 \%$ na $10 \mathrm{mgl}^{-1}$, dok niže koncentracije nisu bile detektibilne. Na osnovu toga zaključeno je da uzorci moraju biti analizirani odmah nakon uzorkovanja ili čuvani u zamrzivaču na $-20{ }^{\circ} \mathrm{C}$.

Postignuti postotak ekstrakcije fenola iz urina iznosi od 73,8 do $111,2 \%$, odnosno zabilježen je trend pada postotka efikasnosti ekstrakcije s porastom koncentracije fenola. Rezultati su prikazani u tablici 1 . Na slici 4 prikazani su kromatogrami mobilne faze pri obje valne duljine.

Reprezentativni kromatogrami izvornog i špikanog urina (koncentracije $10 \mathrm{mgl}^{-1}$ ) pri valnim duljinama $270 \mathrm{i}$ $218 \mathrm{~nm}$ prikazani su na slikama 5 i 6 .
Tablica 1 - Postotak efikasnosti ekstrakcije fenola (recovery) na $270 \mathrm{~nm}$

Table 1 - Percent recovery of phenol from spiked urine samples at $270 \mathrm{~nm}$

\begin{tabular}{c|c}
\hline $\begin{array}{l}\text { Koncentracija fenola } \\
\text { Phenol concentration } / \mathrm{mg} \mathrm{I}^{-1}\end{array}$ & $\begin{array}{l}\text { Efikasnost ekstrakcije } \\
\text { Recovery } / \%\end{array}$ \\
\hline 1 & 106,7 \\
5 & 99,4 \\
10 & 111,2 \\
25 & 80,8 \\
30 & 73,8 \\
\hline
\end{tabular}
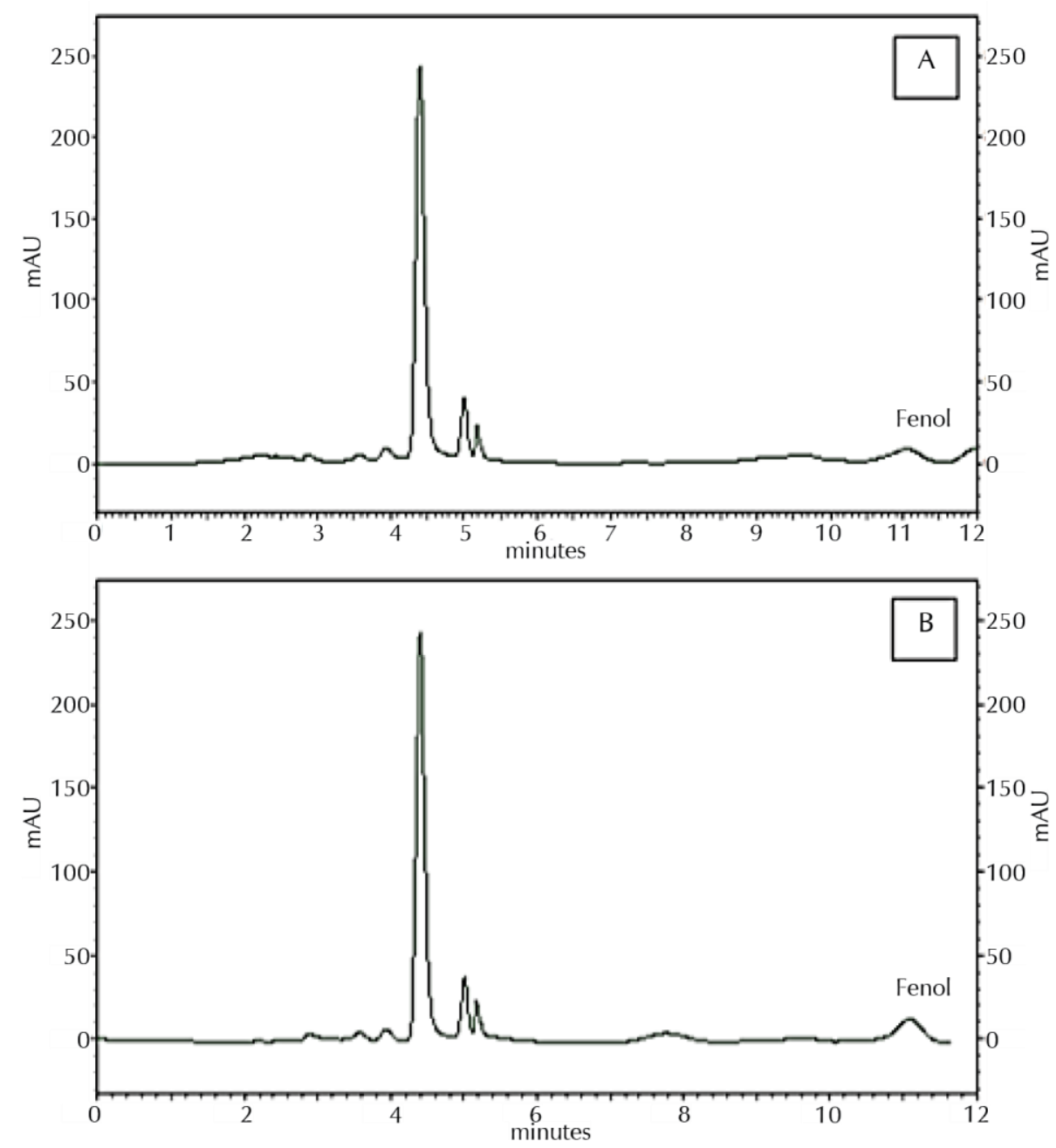

Slika 5 - Kromatogrami: (A) urina na $270 \mathrm{~nm}$; (B) urina koncentracije fenola $10 \mathrm{mgl}^{-1}$ na $270 \mathrm{~nm}$

Fig. 5 - Chromatograms: (A) urine at $270 \mathrm{~nm}$; (B) urine for a phenol concentration of $10 \mathrm{mg} \mathrm{l}^{-1}$ at $270 \mathrm{~nm}$ 

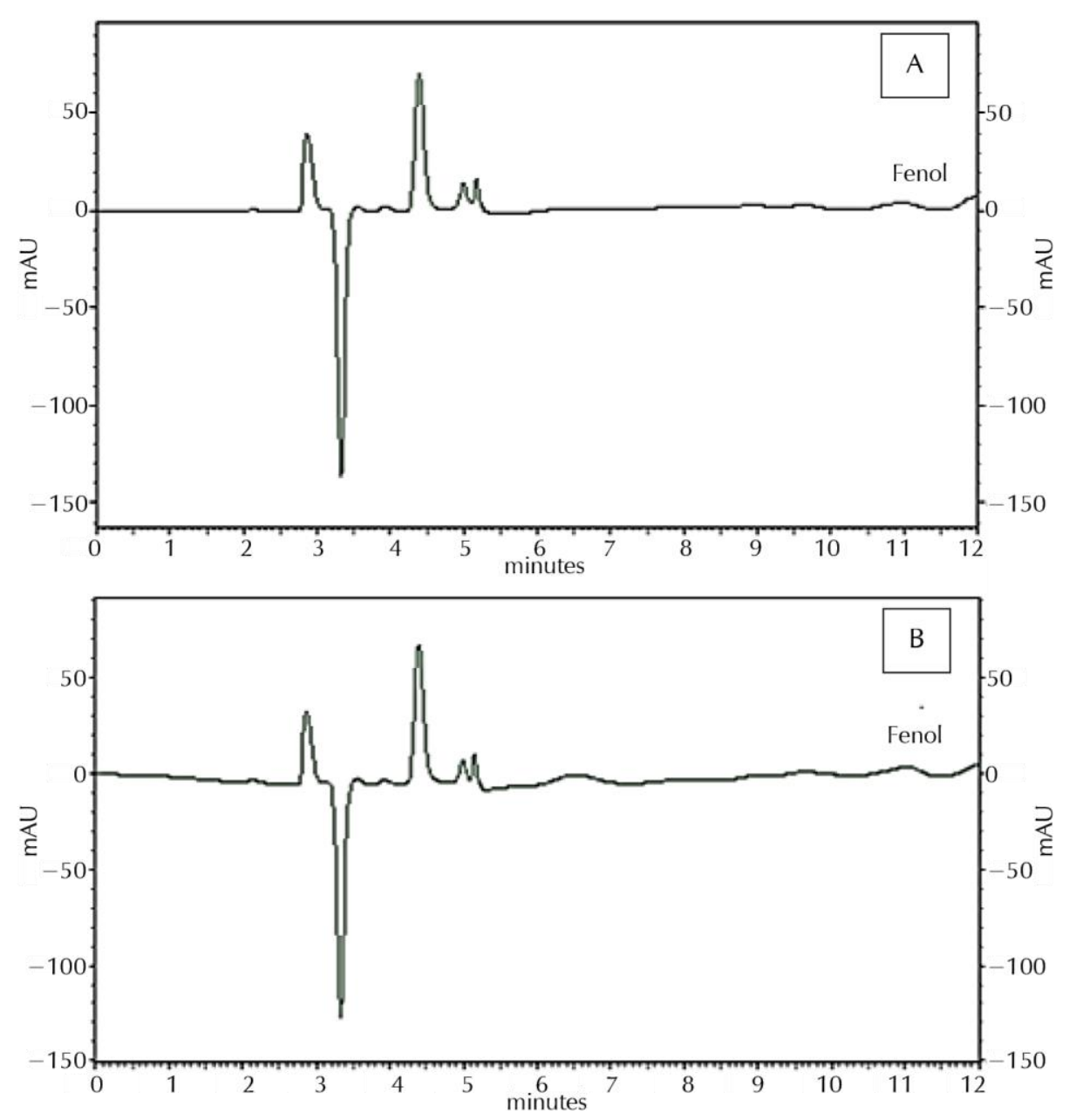

Slika 6 - Kromatogrami: (A) urina na $218 \mathrm{~nm}$; (B) urina koncentracije fenola $10 \mathrm{mgl}^{-1}$ na $218 \mathrm{~nm}$

Fig. 6 - Chromatograms: (A) urine at $218 \mathrm{~nm}$; (B) urine for a phenol concentration of $10 \mathrm{mgl}^{-1}$ at $218 \mathrm{~nm}$ 

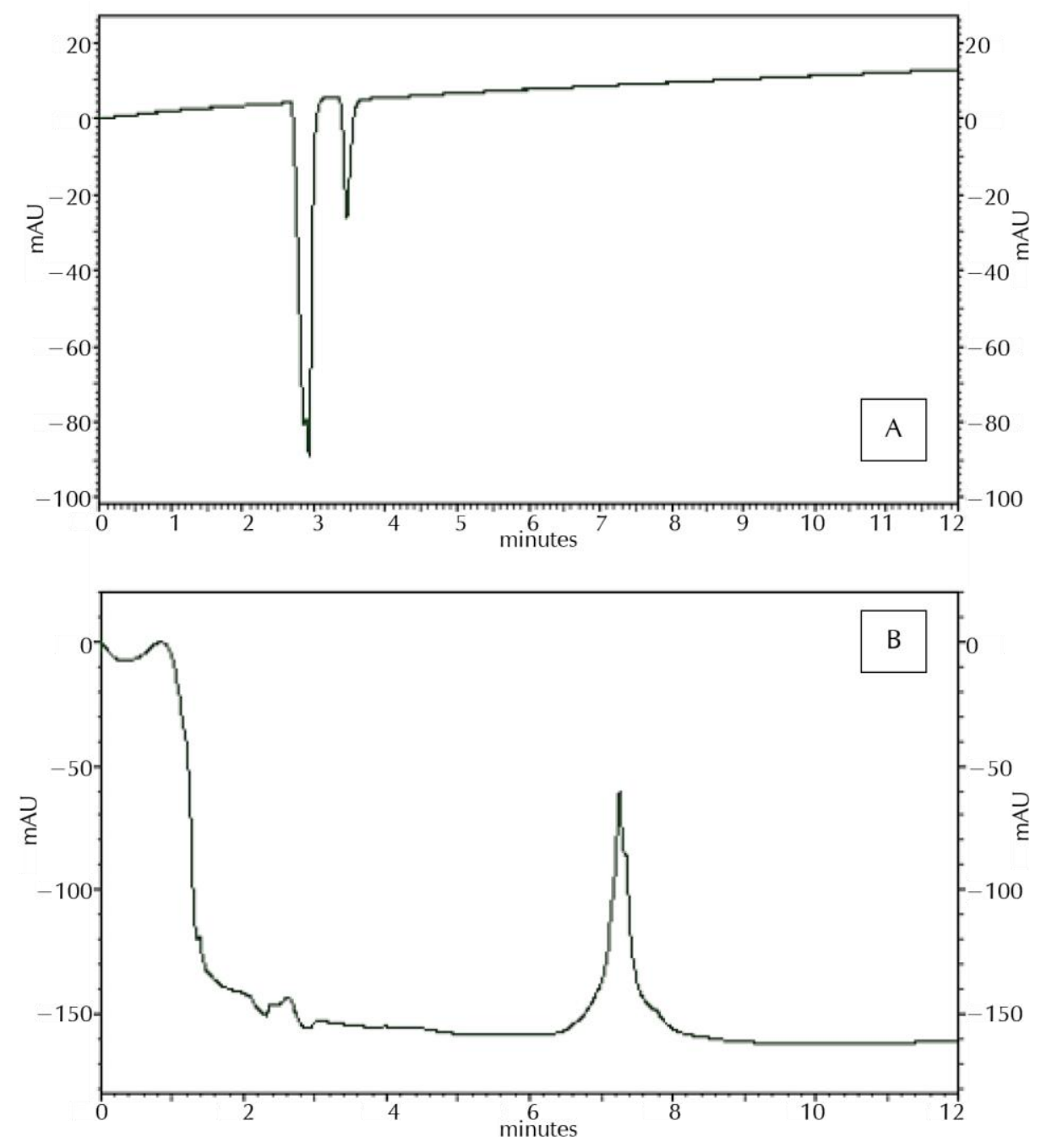

Slika 7 - Kromatogram slijepe probe (destilirana voda) na: (A) $218 \mathrm{~nm}$; (B) $270 \mathrm{~nm}$

Fig 7 - Chromatograms of blank (distilled water): (A) $218 \mathrm{~nm}$; (B) $270 \mathrm{~nm}$

Propuštanjem standarda fenola u vodi evidentirana je kromatografska krivulja fenola na oko $11 \mathrm{~min}$. Na kromatogramima urina kromatografske krivulje između 2,5 i 7,5 min pripadaju drugim komponentama iz urina. Kromatogram slijepe probe pri obje valne duljine prikazan je na slici 7.

\section{Zaključak}

$\mathrm{U}$ opisanim laboratorijskim uvjetima pokazalo se da objavljene metode nisu uvijek ponovljive $u$ izvornom obliku, te da su potrebne određene izmjene. Analizom nije zabilježena zadovoljavajuća preciznost na $218 \mathrm{~nm}$. Stoga je preporuka da se za detekciju fenola u uzorcima urina primjenjuje valna duljina $270 \mathrm{~nm}$. $U$ odnosu na odabrane metode za testiranje ponovljivosti postignuta je granica detekcije $\left(1,47 \mathrm{mg} \mathrm{l}^{-1}\right)$ te linearnost $\mathrm{i}$ efikasnost ekstrakcije fenola u većem koncentracijskom rasponu.

\section{ZAHVALA}

Ovaj rad je financiralo Federalno ministarstvo obrazovanja i nauke, Bosna i Hercegovina u 2016. godini.

\section{Literatura \\ References}

1. S. M. Rappaport, S. Kim, Q. Lan, G. Li, R. Vermeulen, S. Waidyanatha, L. Zhang, S. Yin, M. T. Smith, N. Rothmane, Human Benzene Metabolism Following Occupational and Environmental Exposures, Chem. Biol. Interact. 184 (1-2) (2010) 189-195,

doi: https://doi.org/10.1016/j.cbi.2009.12.017.

2. M. J. Schlosser, R. D. Shurina, G. F. Kalf, Metabolism of Phenol and Hydroquinone to Reactive Products by Macrophage 
Peroxidase or Purified Prostaglandin H Synthase, Environ. Health Perspect. 82 (1989) 229-237, doi: https://doi.org/10.1289/ehp.8982229.

3. G. L. Phipps, G. W. Holcombe, J. T. Fiandt, Acute toxicity of phenol and substituted phenols to the fathead minnow, Bull. Environ. Contam. Toxicol. 26 (1) (1981) 585-593, doi: https://doi.org/10.1007/BF01622141.

4. A. Nickheslat, M. M. Amin, H. Izanloo, A. Fatehizadeh, S. M. Mousavi, Phenol Photocatalytic Degradation by Advanced Oxidation Process under Ultraviolet Radiation Using Titanium Dioxide, J. Environ. Public Health 2013 (2013), doi: https://doi.org/10.1155/2013/815310.

5. B. Radojičić, Određivanje fenola u urinu u grupi radnika izloženih benzenu, Arh. Hig. Rada 26 (1975) 209-212.

6. L. L. Needham, S. L. Head, R. E. Cline, Determination of Phenols and Cresols in Urine by Gas Chromatography, Anal. Lett. 17 (14) (1984) 1555-1565,

7. doi: https://doi.org/10.1080/00032718408065331.

8. M. Yoshikawa, K. Arashidani, Y. Kodama, A simple determination of phenol in urine by high performance liquid chromatography, Sangyo Igaku 27 (2) (1985) 83-89, doi: https://doi.org/10.1539/joh1959.27.83.
9. M. Chen, P. Zhu, B. Xu, R. Zhao, S. Qiao, X. Chen, R. Tang, D. Wu, L. Song, S. Wang, Y. Xia, X. Wang, Determination of nine environmental phenols in urine by ultra-high-performance liquid chromatography-tandem mass spectrometry, J. Anal. Toxicol. 36 (9) (2012) 608-615, doi: https://doi.org/10.1093/jat/bks072.

10. K. Nakashima, S. Kinoshita, M. Wada, N. Kuroda, W. R. Baeyens, HPLC with fluorescence detection of urinary phenol, cresols and xylenols using 4-(4,5-diphenyl-1Himidazol-2-yl)benzoyl chloride as a fluorescence labeling reagent, Analyst 123 (11) (1998) 2281-2284, doi: https://doi.org/10.1039/a804582h.

11. M. A. Alawi, Determination of Benzene and its Metabolite Phenol in the Urine Samples of Gas-Station Workers in the Greater Amman Municipality, Dirasat Pure Sci. 35 (2) (2008) 175-179.

12. A. M. Birkett, G. P. Jones, J. G. Muir, Simple high-performance liquid chromatographic analysis of phenol and p-cresol in urine and feces, J. Chromatogr. B 674 (1995) 187-191, doi: https://doi.org/10.1016/0378-4347(95)00324-X.

\section{SUMMARY}

\section{Reproducibility of the Selected Methods for Determination of Phenol in Urine by High Performance Liquid Chromatography

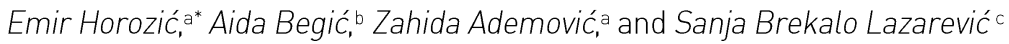

Determination of phenol in urine is considered as a suitable biomarker of benzene exposure, which is classified as Group A carcinogen by the International Agency for Cancer Research (IARC) and the Environmental Protection Agency (EPA).

The aim of this work was to test reproducibility of several published high performance liquid chromatography (HPLC) methods for phenol determination in urine samples. Previous methods mostly included additional equipment (e.g. fluorescence detector) or an additional step in a sample preparation protocol (e.g. derivatization or steam distillation) which is time consuming and can also cause the loss of analyte. The method that was chosen in this work showed good reproducibility with certain modifications in chromatographic conditions and sample preparation protocol. Optimisation of the method included changes in wavelength, constituents, and the flow rate of mobile phase, and excluded the addition of internal standard in sample preparation protocol. Mobile phase consisted of distilled water: methanol: glacial acetic acid (65:34: $1 \mathrm{v} / \mathrm{v} \%)$, and Selectra C18 $(4.6 \times 250 \mathrm{~mm}, 5 \mu \mathrm{m})$ column was used. Chromatographic conditions included the flow rate of $1 \mathrm{ml} \mathrm{min}^{-1}$, room temperature, wavelength at $218 \mathrm{~nm}$ and $270 \mathrm{~nm}$, and an injection volume of $20 \mu \mathrm{l}$. At $270 \mathrm{~nm}$, linearity was shown in the range of concentrations of 1-30 mgl-1 $\left(y=10290 x+15138 ; R^{2}=0.9932\right)$, while the achieved percentage of recovery was between $73.8 \%$ and $111.2 \%$ for the tested concentrations.

\section{Keywords}

Phenol, extraction, urine, HPLC

\footnotetext{
${ }^{a}$ Faculty of Technology, University of Tuzla, Univerzitetska 8, 75000 Tuzla, B\&H

${ }^{b}$ Faculty of Pharmacy, University of Tuzla, Univerzitetska 8, 75000 Tuzla, B\&H

' Faculty of Medicine, University of Tuzla, Univerzitetska 1, 75000 Tuzla, B\&H
} 